\title{
Renal Pelvis and Ureter Cancer pTis TNM
} Finding v7

National Cancer Institute

\section{Source}

National Cancer Institute. Renal Pelvis and Ureter Cancer PT is TNM Finding V7. NCI

Thesaurus. Code C89310.

Renal pelvis and ureter cancer with a finding of carcinoma in situ. (from AJCC 7th Ed.) 